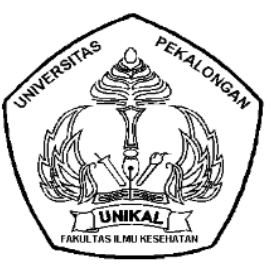

JURNAL KESEHATAN PENA MEDIKA VOL 11 (1) JUNI 2021

PENA MEDIKA

FAKULTAS ILMU KESEHATAN UNIVERSITAS

PEKALONGAN

http://jurnal.unikal.ac.id/index.php/medika ISSN : 2086-843X

\title{
Peran Dongeng dalam Menjaga Perilaku Sehat Ibu dan Anak di Masa Pandemi
}

\author{
Basuki Sarwo Edi ${ }^{1 \bowtie}$ Ratu Wardarita ${ }^{2}$ \\ ${ }^{1}$ Balai Bahasa Provinsi Sumatera Selatan \\ 2. Universitas PGRI Palembang \\ \basukisarwoedi@yahoo.co.id
}

\begin{abstract}
ARTICLE INFO
Accepted : 02 Juni 2021

Approve : 15 Juni 2021

Publish : 31 Juni 2021
\end{abstract}

\begin{abstract}
Fairy tales are a type of children's literature. Fairy tales have various functions, including as entertainment for children, as a means of passing on values that are believed to be true by society, as a way to instill character in children. This study aims to determine the role of fairy tales in maintaining the healthy behavior of mothers and children during a pandemic. This type of research is descriptive research. The research data source is in the form of fairy tales that can be used in healthy behavior. Fairy tales can strengthen the relationship between mother and child in building healthy behavior. Based on the results of data analysis and discussion, fairy tales can maintain healthy behavior for mothers and children: (1) develop children's imaginations; (2) able to stimulate children to improve their language skills; (3) Generating children's interest in reading by telling stories; (4) Building children's emotional intelligence by providing examples through the characters in the stories we tell; (5) Forming Children's Empathy; (6) Adding insight and increasing moral values; (7) train memory; (8) Strengthen the relationship between you and your child; (9) Helping to develop children's listening skills; and (10) Helping children to have healthy sleep patterns.
\end{abstract}

Key words: Role, Fairy Tales, Healthy Behavior, Pandemic

\section{ABSTRAK}

Dongeng merupakan salah satu jenis sastra anak. Dongeng memiliki berbagai fungsi, antara lain sebagai hiburan untuk anak, sebagai sarana untuk mewariskan nilai-nilai yang diyakini kebenarannya oleh masyarakat, sebagai salah satu cara menanamkan budi pekerti pada anak. Penelitian ini bertujuan untuk mengetahui peran dongeng dalam menjaga perilaku sehat ibu dan anak di masa pandemi. Jenis penelitian ini adalah penelitian deskripsi. Sumber data penelitian berupa dongeng yang bisa digunakan dalam perilaku sehat. Dongeng dapat mengeratkan hubungan Ibu dan anak dalam membangun perilaku sehat. Berdasarkan hasil analisis data dan pembahasannya, dongeng dapat menjaga perilaku sehat Ibu dan anak: (1) mengembangkan imajinasi anak; (2) mampu merangsang anak-anak dalam meningkatkan keterampilan berbahasa mereka; (3) 
Membangkitkan minat baca anak dengan mendongeng; (4) Membangun kecerdasan emosional anak dengan memberikan contoh melalui tokoh dalam cerita yang kita dongengkan; (5) Membentuk Rasa Empati Anak; (6) Menambah wawasan dan nilai moral bertambah; (7) melatih daya ingat; (8) Mempererat hubungan Anda dan anak; (9) Membantu mengembangkan keterampilan mendengarkan anak; dan (10) Membantu anak memiliki pola tidur yang sehat.

\section{Kata Kunci: Peran, Dongeng, Perilaku Sehat, Pandemi}

\section{PENDAHULUAN}

Dongeng memiliki peran penting dalam menjaga harmonisasi hubungan ibu dan anak. Dongeng mengeratkan kasih sayang antara ibu dan anak. Dongeng merupakan komunikasi yang ampuh antara Ibu dan anak. Hal ini sesuai dengan pendapat Effendy (2006:9) komunikasi berarti sama makna. Istilah komunikasi tersebut berasal dari kata latin communicatio dan bersumber dari kata communis yang berarti sama. Komunikasi memiliki dua sifat, yaitu informatif dan persuasif. Melalui kata lain komunikasi akan terjadi jika terdapat kesamaan makna mengenai hal yang dibicarakan oleh pihak yang berkomunikasi. Komunikasi bersifat informatif, yaitu menyampaikan informasi kepada lawan bicara. Selain itu komunikasi juga bersifat persuasif agar lawan bicara bersedia menerima paham atau keyakinan dari informasi yang disampaikan.
Di masa pandemi, Ibu dapat lebih mendekatkan hubungan dengan anak. Karena anak bersekolah dari rumah. Ibu yang bekerja di kantor pun terkadang menggunakan sistem piket sehingga memungkinkan terjadi komunikasi yang instens antara Ibu dan anak.

Dongeng juga berfungsi menanamkan nilai-nilai yang sangat penting dalam perilaku perkembangan anak. Menurut Danandjaja (2012:83) dongeng adalah cerita pendek kolektif kesusastraan lisan. Dongeng adalah cerita prosa rakyat yang tidak dianggap benar-benar terjadi. Dongeng diceritakan terutama untuk huburan, walaupun banyak juga yang melukiskan kebenaran, kasih sayang, pelajaran moral, atau bahkan sindiran terhadap sesuatu.

Kadang-kadang di pikiran orang awam dongeng dapat berupa cerita tentang peri. Dongeng bisa saja berupa bermacam-macam cerita. Hal ini sejalan 
http://jurnal.unikal.ac.id/index.php/medika ISSN : 2086-843X

dengan pendapat Einon (2006:27) dongeng adalah cerita yang berisi kisahkisah menakutkan atau menyeramkan, seperti ibu tiri yang jahat terhadap anakanaknya bahkan terkadang kejam kepada anak-anaknya. Meski demikian cerita-cerita tersebut disukai oleh anaksepanjang waktu. Hal itu disebabkan memberikan kesempatan kepada anak untuk berimajinasi dengan berbagai peristiwa dan semakin manyayangi Ibu mereka secara nyata. Mereka berbahagia memiliki Ibu yang selalu penuh kasih kepada orang tua mereka. Dongeng merupakan cerita khayalan tingkat tinggi disampaikan dari mulut ke mulut berisi penenaman nilai-nilai yang sarat dengan makna kebaikan. Dongeng di sam-paikan secara turuntemurun. Cerita dalam dongeng berkisah tentang kebaikan melawan kejahatan. Kisah dalam dongeng kejahatan selalu kalah oleh kebaikan. Dongeng biasanya menceritakan tentang masyarakat, sejarah, fenomena alami dan perjuangan terhadap harapan untuk sebuah perubahan.

Dongeng dapat dikatakan berperan dalam menjaga perilaku yang baik dan bernilai sejak anak-anak masih berusia kanak-kanak.

Menurut Aarne dan Thomson (2004:20) dongeng dibagi dalam empat golongan besar, yaitu:

(1) dongeng binatang (animal tales)

(2) Dongeng biasa (ordinary folktale)

(3) Lelucon dan anekdot (jokes and anecdotes)

(4) Dongeng berumus (formula tales)

Di dalam berbagai jenis dongeng, dongeng tersebut tetap saja memiliki dungsi yang luar biasa dalam perkembangan anak. Menurut Lasswell (dalam Effendy, 2006), Komunikasi memiliki beberapa unsur, diantaranya: (1) komunikator (communicator, source, sender), (2) Pesan (message), (3) Media (channel, media), (4) Komunikan (communicant, communicate, receiver, recipient), (5) efek (effect, influence).

Proses komunikasi tersebut akan terjadi jika terdapat kelima unsur-unsur tersebut.

Sementara itu Komunikasi berdasarkan prosesnya dibedakan menjadi dua, yaitu komunikasi primer 


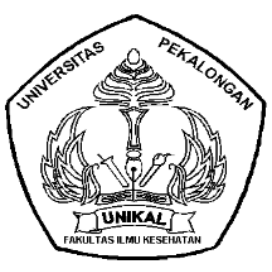

JURNAL KESEHATAN PENA MEDIKA VOL 11 (1) JUNI 2021

PENA MEDIKA

FAKULTAS ILMU KESEHATAN UNIVERSITAS

PEKALONGAN

http://jurnal.unikal.ac.id/index.php/medika ISSN : 2086-843X

dan komunikasi sekunder. Komunikasi

primer adalah komunikasi dengan

proses penyampaian pikiran atau

perasaan seseorang kepada orang lain dengan menggunakan lambang atau simbol sebagai media. Simbol yang digunakan dalam komunikasi primer adalah bahasa, isyarat, atau gambar. Komunikasi sekunder adalah komunikasi dengan proses penyampaian pesan oleh seseorang oleh orang lain dengan menggunakan alat atau sarana sebagai media kedua setelah lambang sebagai media pertama.

Dongeng Ibu kepada anak merupakan komunikasi primer yang menyebabkan terjadinya fungsi komunikasi, substansi, dan penanaman nilai-nilai kepada anakanak.

Dongeng termasuk salah satu bentuk cerita rakyat. Menurut Sulistyarini (2006:13), cerita rakyat mengandung nilai luhur bangsa, terutama nilai-nilai budi pekerti maupun ajaran moral. Apabila cerita rakyat itu dikaji dari sisi nilai moral, maka dapat dipilah menjadi nilai moral individual, nilai moral sosial, dan nilai moral religi.
Piaget membagi

tahap

perkembangan moral menjadi

(a)

Moralitas heteronom (usia 4-7 tahun),

(b) Transisi (7-10 tahun), (c) Moralitas Otonom (10 tahun keatas). Anak usia 78 tahun berada pada tahap transisi, yaitu tahap peralihan dari pemikiran bahwa aturan-aturan tentang baik-buruk dibuat mutlak oleh orang dewasa dan Tuhan sehingga tidak seorangpun bisa merubah menjadi pemikiran bahwa aturan-aturan tersebut hanya alat yang dibuat secara kooperatif dengan orang dewasa (Nur'ain, 2007:21).

Dongeng menjadi penjaga hubungan kasih sayang ibu dan anak. Membina dan merawat cerita rakyat (dongeng) yang disampaikan dari mulut ke mulut antargenerasi.

\section{METODE}

Penelitian ini merupakan penelitian deskriptif kualitatif yang berupaya menjelaskan fenomena mengenai peran dongeng dalam menjaga perilaku sehat ibu dan anak di masa pandemi.

Penelitian ini bertujuan untuk mengetahui peran dongeng dalam menjaga perilaku sehat ibu dan anak di masa pandemi. Jenis penelitian ini 
http://jurnal.unikal.ac.id/index.php/medika ISSN : 2086-843X

adalah penelitian deskripsi. Teknik penelitian yang digunakan adalah teknik dasar dan lanjutan. Teknik dasar yang digunakan adalah wawancara kepada informan. Teknik lanjutan dengan sadap dan catat. Sumber data penelitian berupa dongeng yang bisa digunakan dalam perilaku sehat. Dongeng dapat mengeratkan hubungan Ibu dan anak dalam membangun perilaku sehat.

\section{HASIL PENELITIAN}

Dongeng yang dapat digunakan untuk memperat kasih sayang Ibu dan anak adalah

\section{(1) Dongeng Anak Umang}

Cerita ini dibawah dengan kehidupan dua anak yang ditinggal mati ibunya. Hidup bersama dengan ayah dan ibu tirinya sangat tidak menyenangkan karena sering tidak diberi makan. Dengan keadaan yang demikian, kedua anak itu akhirnya melarikan diri.

Cerita berkembang dengan peristiwa pelarian kedua orang anak itu ke dalam hutan. Di dalam hutan mereka menemukan sebuah pondok besar yang tidak ada penghuninya. Mereka masuk dan menemukan makanan yang banyak, kemudian mereka makan dengan lahapnya. Hari pun semakin gelap dan mereka pun tidur di dalam sebuah kamar di pondok itu.

Konflik mulai terjadi ketika kedua nak itu merasa cemas dan takut kalaukalau pemiliknya marah. Penghuni rumah itu thu ada manusia di dalam pondok mereka. Hingga malam pun tiba, ketiga hantu besar pemilik pondok itu tidak mau mengusik kedua anak itu yang sedang tertidur pulas.

Puncak cerita terjadi ketika kedua anak itu ditanya oleh penghuni pondok itu. Kedua anak itu menceritakan apa yang terjadi pada diri mereka. Setelah mendengar cerita itu, hantu penghuni pondok itu yakin bahwa kedua anak itu adalah anak kandungnya. Ia mengaku sebagai ibunya yang telah meninggal. Oleh karena itu, ia meminta untuk mencari jeruk tujuh ikat untuk mandi. Pada saat mandi bila ada sesuatu yang aneh, janganlah takut dan mintalah sesuatu, mudah-mudahan terkabul, apa pun permintaan mereka. Kedua bersaudara itu meminta agar mereka bisa berkumpul kembali dengan keluarga. Terkabullah permintaannya 
bahwa mereka ingin hidup sejahtera bersama keluarganya.

Cerita berakhir dengan bertemunya kembali kedua anak itu dengan ayahnya yang kebetulan mencari di dekat pondok mereka di tengah hutan. Akhirnya mereka sekeluarga dapat berkumpul kembali dan hidup bersama keluarga dengan bahagia.

\section{(2) Dongeng ANAK YATIM DUA} BERSAUDARA

Cerita ini merupakan cerita rakyat Aji. Cerita ini dapat kita temukan di kalangan masyarakat Kecamatan Muaradua, Kabupaten Ogan Komering Ulu Selatan.

Cerita ini mengisahakan kehidupan dua kakak beradik yang telah ditinggalkan oleh kedua orang tuanya. Ceritanya diawali ketika kakak dua breradik tersebut menemukan sebutir telur yang aneh di sawah. Setelah telur itu dimasak dan dimakan oleh kakak dua beradik tersebut, si kakak menjadi haus dan minum sebanyak-banyaknya sehingga berapa banyak air yang diberikan adiknya tidak pernah cukup. Sang kakak meminta kepada adiknya untuk diantarkan ke pancuran agar dapat minum sepuasnya. Keesokan harinya adiknya sangat terkejut ketika melihat ke pancuran, ternyata kakaknya telah berubah menjadi seekor naga. Naga tersebut mengajak adiknya pergi ke Lubuk Semendawali untuk menaklukan buaya yang ada di lubuk itu, sehingga dia dapat menempati lubuk tersebut. Sesampainya di pinggir lubuk naga (kakaknya) menyuruh adiknya menunggu di atas pohon beringin yang ada di pinggir lubuk, sambil meminta memperhatikan pertempurannya dengan buaya penunggu lubuk. Awalnya naga kalah dan hamper mati, tapi adiknya mengobatinya dengan minyak dan lidi yang dibawanya. Setelah beristirahat seminggu naga kembali masuk ke lubuk untuk membunuh buaya dan akhirnya naga berhasil membunuh buaya dan menjadi penguasa lubuk tersebut. Naga meminta adiknya untuk tetap tinggal di atas pohon beringin dekat lubuk tersebut sehingga kalau ada apa-apa naga dapat membantunya. Suatu hari datanglah seorang pemburu ke dekat lubuk tersebut. dia terkejut melihat seorang gadis cantik ada di atas pohon beringin, kemudian pemburu tersebut berbicara dengan gadis di atas pohon 
http://jurnal.unikal.ac.id/index.php/medika ISSN : 2086-843X

(adik naga) dan meminangnya. Gadis cantik tersebut setuju kalau kakaknya yang telah berubah menjadi naga tersebut juga setuju. Setelah mendapat ijin dari kakaknya. Si adik (gadis cantik) dibawa pemburu ke rumahnya untuk dinikahinya. Selagi pemburu mempersiapkan pernikahan dan memberitahu orang tuanya, si gadis dimintanya menunggu di atas pohon beringan. Namun pada hari pernikannya sesuatu terjadi, gadis itu tertukar dengan gadis pembantu keluarga si pemburu. Sehingga si pemburu bukan menikahi gadis cantik adik naga, melainkan menikahi Tembikar pembantunya. Dengan sedih gadis cantik tersebut mendongeng kepada beberapa orang bahwa telah terjadi kesalahan dalam perkawinan si pemburu dan pulang ke lubuk di mana kakaknya tinggal. Menyadari kesalahan tersebut pemburu menyuruh anak buahnya untuk menjemputnya. Setelah dijemput akhirnya gadis tersebut menikah dengan si pemburu.

\section{(3) Dongeng Asal Beruk Berekor Pendek}

Pada suatu hari beruk akan menolong harimau dari ancaman sang kancil. Ekornya dan ekor harimau diikat menjadi satu. Kancil yang cerdik itu mengatakan kepada beruk, bahwa harimau yang diantarkan beruk itu sebagai pembayar hutang bapaknya. Harimau berlari ketakutan. Beruk terjatuh dan terseret oleh harimau. Akhirnya ekor beruk putus sehingga menjadi pendek. Cerita ini populer di masyarakat Komering.

(4) Dongeng Batu Menangis

Batu Menangis menceritakan nasib seorang anak gadis yang durhaka terhadap ibunya. Kerjanya hanya bersenang-senang, tidak mau membantu ibunya. Ketika bertemu dengan seorang pemuda ia tidak mau mengakui bahwa perempuan itu adalah ibunya sehingga ibunya merasa tersinggung. Kemudian ibunya pergi ketepi sungai dan berdoa kepada Tuhan agar anak gadisnya sadar bahwa ia telah menghina ibunya. Anak gadis itu akhirnya menjadi batu. Cerita ini popular di masyarakat di Ogan. 
http://jurnal.unikal.ac.id/index.php/medika ISSN : 2086-843X

(5) Dongeng Beruk Berperahu Kulit

\section{Timun}

Beruk Berperahu Kulit Timun adalah salah satu cerita rakyat Aji. Cerita ini dapat kita temukan di kalangan masyarakat Kecamatan Muradua, Kabupaten Ogan Komering Ulu Selatan.

\section{Cerita Beruk Berperahu Kulit} Timun mengisahkan tentang kelakuan Beruk yang tidak mau disebut beruk. Cerita ini berawal dari perjalanan beruk, buruga, dan burung pipit di atas perahu yang terbuat dari kulit pisang. Setiap melewati desa, banyak orang memuji betapa bagusnya burung pipit yang seperti kiyai, beruga seperti beruga pikat, tapi orang-orang tidak memuji beruk, mereka mengatakan beruk seperti beruk. Beruk pikir orang tidak memujinya karena tempat duduknya yang di tengah, maka dia minta bertukar tempat dengan beruga. Ketika melewati desa lagi, orang-orang tetap memuji burung pipit dan beruga, tapi beruk tetap dikatakan seperti beruk. Beruk belum juga puas, kali ini dia meminta bertukar tempat dengan burung pipit, dan ketika melewati sebuah desa lagi, orang-orang masih tetap memuji burung pipit seperti kiyai, beruga seperti beruga pikat, tapi beruk tetap dikatakan seperti beruk. Beruk menjadi kesal dan marah karena tidak ada yang memujinya sehingga dia menggigit perahu kulit timunnya sampai berlubang dan tenggelam. Beruga dan urung pipit dapat terbang menyelamatkan diri, sementara beruk mati tenggelam karena tidak dapat berenang.

Dongeng-dongeng tersebut berasal dari wilayah penutur di Sumatera Selatan.

Hal ini sesuai dengan pendapat Subiyantoro (2012), dongeng memiliki nilai-nilai karakterl yang meliputi (1) kepatuhan, (2) keberanian, (3) rela berkorban, (4) jujur, (5) adil dan bijaksana, (6) menghormati dan menghargai, (7) bekerja keras, (8) menepati janji, (9) tahu balas budi, (10) rendah hati, dan (12) hati-hati dalam bertindak.

Selain itu, Nilai-nilai moral sosial meliputi (1) bekerjasama, (2) suka menolong, (3) kasih sayang, (4) kerukunan, (5) suka memberi nasihat, (6) peduli nasib orang lain, dan (7) suka mendoakan orang lain. Sementara itu, nilai-nilai moral religi meliputi (1) 
percaya kekuasaan Tuhan, (2) percaya adanya Tuhan, (3) berserah diri kepada Tuhan atau bertawakal, dan (4) memohon ampun kepada Tuhan.

Dongeng memiliki nilai-nilai moral yang meliputi (1) kepatuhan, (2) keberanian, (3) rela berkorban, (4) jujur, (5) adil dan bijaksana, (6) menghormati dan menghargai, (7) bekerja keras, (8) menepati janji, (9) tahu balas budi, (10) rendah hati, dan (12) hati-hati dalam bertindak. Selain itu, Nilai-nilai moral

Dongeng-dongeng tersebut tentu saja disesuaikan dengan usia anak. Alur cerita juga dapat disesuaikan dengan situasi. Bahkan Ibu pun dapat menciptakan kreativitas menciptakan dongeng tersendiri bagi anak. Misal dongeng-dongeng yang berhubungan dengan Pandemi Covid-19.

\section{DISKUSI}

Dongeng-dongeng yang diceritakan Ibu kepada anak dapat:

(1) mengembangkan imajinasi anak

Dengan adanya dongeng tersebut imajinasi anak berkembang sosial meliputi (1) bekerjasama, (2) suka menolong, (3) kasih sayang, (4) kerukunan, (5) suka memberi nasihat, (6) peduli nasib orang lain, dan (7) suka mendoakan orang lain. Sementara itu, nilai-nilai moral religi meliputi (1) percaya kekuasaan Tuhan, (2) percaya adanya Tuhan, (3) berserah diri kepada Tuhan atau bertawakal, dan (4) memohon ampun kepada Tuhan.

sesuai dengan usia dan daya tangkap anak. Hal ini akan menimbulkan kreativitas bagi anak.

(2) mampu merangsang anak-anak dalam meningkatkan keterampilan berbahasa mereka

Hubungan berbahasa merupakan hubungan yang timbal balik. Jika menyimak bagus maka berbicara anak pun akan bagus. Dongeng dapat meningkatkan kemampuan keterampilan berbahasa anak.

(3) Membangkitkan minat baca anak dengan mendongeng

\section{Dengan} mendongeng menciptakan rasa ingin tahu dan minta anak untuk mencari tahu lebih lanjut 


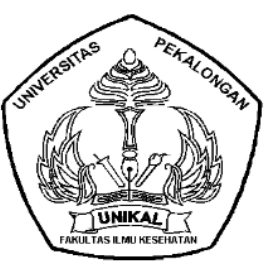

JURNAL KESEHATAN PENA MEDIKA VOL 11 (1) JUNI 2021

PENA MEDIKA

FAKULTAS ILMU KESEHATAN UNIVERSITAS

PEKALONGAN

http://jurnal.unikal.ac.id/index.php/medika ISSN : 2086-843X

mengenai dongeng yang telah

dibacakan/diceritakan Ibu kepada anak.

(4) Membangun kecerdasan emosional anak dengan memberikan contoh melalui tokoh dalam cerita yang kita dongengkan

Anak memiliki kecerdasan emosional dengan tokoh-tokoh yang diceritakan Ibu dalam dongeng. Melalui tokoh timbul rasa kagum anak terhadap karateristik tokoh yang didongengkan oleh Ibu. Bahkan anak dapat mencontoh tingkah laku tokoh yang didongengkan. Karena itu, berilah contoh tokoh yang baik dan sesuai harapan Ibu.

(6) Membentuk Rasa Empati Anak

Rasa empati akan timbul dari diri si anak jika Ibu menceritakan tokoh yang meliki karakter yang patud dan dapat dicontoh oleh anak.

(7) Menambah wawasan dan nilai moral bertambah

Anak dapat bertambah wawasan dengan mendengarkan dongeng yang diceritakan Ibu. Moral anak pun akan tertata dengan menampilkan tokoh-tokoh yang santun dan memiliki nilai-nilai budi

pekerti yang baik.

(8) melatih daya ingat

Dongeng juga menjadikan anak memiliki daya ingat dan kecerdasan yang tajam dalam mengingat cerita. Ibi dapat mengulang cerita dan anak dapat melanjutkan alur cerita tersebut.

(9) Mempererat hubungan Anda dan anak

Dongeng dapat mempererat kedekatan dan kasih sayang Ibu dan anak. Dongeng merupakan sarana yang baik untuk memperkukuh hubungan Ibu dan anak.

(9) Membantu mengembangkan keterampilan mendengarkan anak

Keterampilan mendengarkan anak dapat teruji ketika menyimak cerita yang diceritakan oleh Ibu.

(10) Membantu anak memiliki pola tidur yang sehat.

Dongeng juga mengajarkan kepada anak untuk memiliki pola hidup yang 
sehat. Anak akan tidur sesuai jadwal dan displin setiap waktu.

\section{KESIMPULAN}

Dongeng merupakan salah satu jenis sastra lisan yang disampaikan dari mulut ke mulut melalui pewarisan lisan, berkembang dari generasi ke generasi. Dongeng memiliki berbagai fungsi, antara lain sebagai hiburan untuk anak, sebagai sarana untuk mewariskan nilainilai yang diyakini kebenarannya oleh masyarakat, sebagai salah satu cara menanamkan nilai-nilai yang sarat makna dan budi pekerti pada anak. Anak yang biasanya mendengarkan dongeng yang dilantunkan oleh Ibunya biasanya memiliki keterampilan berbahasa yang baik, mencakup memiliki daya simak dan kemampuan berbicara dengan baik.

\section{REFERENSI}

Aarne, Antti dan Stith Thompson. 2004. The Types of The Folktale (a Classification and Bibliography). Academia Scientiarum Fennice. Soumalainen Tieedeakatemia.

Effendy, Ojong Uchjana. 2006. Ilmu Komunikasi teori dan praktek. PT. Remaja Rosdakarya. Bandung
Einon, Dorothy.2006. Learning Early.Jakarta : Dian Rakyat.

Danandjaja, James. 2012. Folklor Indonesia: Ilmu Gosip, Dongeng, dan lain-lain. Grafiti Pres, Jakarta.

Hidayah, Rifa. 2009. Psikologi Pengasuhan Anak. Malang: UINMalang Press.

Nur'ain, $\quad$ Farida.2007.Pedoman Mendongeng untuk Orang tua dan Pendidik. Afra. Surakarta.

Sulistyarini, Dwi. 2006. Nilai Moral dalam Cerita Rakyat sebagai Sarana Pendidikan Budi Pekerti, (Online)/ diunduh 17 Januari 2021.

Subiyantoro, 2012. Membangun Karakter Bangsa Melalui Cerita Rakyat Nusantara 